\title{
Detection of IMP and VIM genes in Pseudomonas aeruginosa isolated from Egyptian patients
}

\author{
Nermine EL Maraghy ${ }^{1}$, Manal Said ${ }^{2}$, Rasha Emad ${ }^{3}$, Mona Salama ${ }^{3}$, Abdullah Hashish ${ }^{4}$
}

\author{
${ }^{1}$ Medical Microbiology and Immunology Department, Faculty of Medicine, Suez Canal \\ University, Ismailia, Egypt \\ ${ }^{2}$ Medical Biochemistry Department, Faculty of Medicine, Suez Canal University, \\ Ismailia, Egypt \\ ${ }^{3}$ Clinical Pathology Department, Faculty of Medicine, Port Said University, Port Said, \\ Egypt \\ ${ }^{4}$ Clinical Pathology Department, Faculty of Medicine, Suez Canal University, Ismailia, \\ Egypt
}

Submitted: 23 December 2018

Accepted: 21 April 2019

Arch Med Sci Civil Dis 2019; 4: e58-e63

DOI: https://doi.org/10.5114/amscd.2019.86742

Copyright @ 2019 Termedia \& Banach

\begin{abstract}
Introduction: Metallo- $\beta$-lactamase production among Pseudomonas aeruginosa is a major health problem worldwide. Pseudomonas aeruginosa acquire several mechanisms of resistance towards carbapenems through the production of metallo- $\beta$-lactamases, especially VIM and IMP. The problem of multi-drug-resistant Pseudomonas aeruginosa is increasing all over the world, reaching dangerous levels. The aim of this study was to detect the metallo- $\beta$-lactamases bla $a_{\mathrm{VIM}}$ and bla $a_{\mathrm{IMP}}$ genes in Pseudomonas aeruginosa strains in Suez Canal University Hospital in Ismailia, Egypt.

Material and methods: A cross-sectional descriptive study was conducted on 65 Pseudomonas aeruginosa strains. Genotypic detection of $b l a_{\mathrm{VIM}}$ and bla $a_{\text {IMP }}$ was reached by using polymerase chain reaction.

Results: Out of 65 Pseudomonas aeruginosa strains, bla $a_{v I M}$ gene was present in four females and one male, with an age of $42.9 \pm 18.1$; two cases were isolated from the Oncology Department, and one case each was present in the Burn Unit, Surgery Ward, and Intensive Care Unit. The bla ${ }_{\mathrm{vIM}}$ gene was expressed in four stains, while the bla ${ }_{\text {mp }}$ gene was not expressed in any strain. Conclusions: The carbapenem resistance in our patients can be referred to as metallo- $\beta$-lactamases bla $_{\text {vIM }}$ type. The problem of metallo- $\beta$-lactamases and carbapenem resistance requires ongoing surveillance, strong preventive measures, and implementation of infection control policies and procedures. Also, routine diagnostic laboratory methods should be performed, and synthesis of antimicrobial products with new effecting mechanism should be implemented in hospitals.
\end{abstract}

Key words: metallo- $\beta$-lactamases, bla ${ }_{\mathrm{VIM}}$, bla $a_{1 \mathrm{MP}}$ Egypt.

\section{Introduction}

One of the most prevalent opportunistic organisms is Pseudomonas aeruginosa, which has started to grow worldwide [1]. It is considered as one of the most extensive organisms, resistant to all anti-pseudomonal antibiotics (carbapenems and aminoglycosides) [2]. For this reason, the best choice of treatment is carbapenems, in spite of the incidence of resistance to these antibiotics [3].

\author{
Corresponding author: \\ Nermine EL Maraghy \\ Medical Microbiology \\ and Immunology \\ Department \\ Faculty of Medicine \\ Suez Canal University \\ Ismailia, Egypt \\ Phone: 002/01224117033 \\ E-mail: nermine76@hotmail. \\ com
}


Pseudomonas aeruginosa acquires several mechanisms of resistance towards carbapenems through the production of metallo- $\beta$-lactamases $(M \beta L S)$, especially VIM (Verona integron-encoded metallo $\beta$-lactamase) and IMP (imipenem active metallo- $\beta$-lactamase) $[4,5]$, alteration and/ or loss of OprD (outer membrane porin protein), hyperproduction of AmpC $\beta$-lactamase [6], and increased expression of efflux pump [5].

Carbapenemase resistance belongs to Ambler classes $A, B$, and $D[7,8]$, but $M \beta L$ VIM and IMP belong to Ambler B. M $\beta$ Ls are inhibited by ethylenediaminetetraacetic acid (EDTA) and sodium mercaptoacetic acid (SMA), but they are not affected by $\beta$-lactase inhibitors such as clavulanic acid, sulbactam, and tazobactam [9].

The problem of multi-drug-resistant (MDR) Pseudomonas aeruginosa has augmented all over the world, thus reaching a dangerous level [10]. It is noteworthy that several studies that have been conducted all over the world reveal that the problem of $M \beta L$ in Pseudomonas aeruginosa is increasing in different hospitals in various parts of the world [11-13]. It has thus been necessary to identify these $M \beta L$ Ls and treat them [13].

The aim of the study was to detect the $M \beta L$ bla $_{\mathrm{VIM}}$ and bla ${ }_{\mathrm{IMP}}$ genes in Pseudomonas aeruginosa strains in patients hospitalised in Suez Canal University Hospital, Ismailia, Egypt.

\section{Material and methods}

A cross-sectional, descriptive study was conducted on 65 Pseudomonas aeruginosa strains obtained from clinical specimens from hospitalised patients admitted to the Suez Canal University Hospital in Ismailia during the period from January 2017 to September 2017, because the M $\beta \mathrm{L}$ enzymes had previously been detected phenotypically in the strains [14] by using the modified Hodge test (MHT) and double disk synergy test (DDST) $[15,16]$. Our inclusion criteria were patients admitted to the hospital $48 \mathrm{~h}$ after infection and who had been suffering from it regardless of their age or sex. We excluded those who showed signs or symptoms of infection $48 \mathrm{~h}$ after admission to the hospital and/or those receiving antibiotics $48 \mathrm{~h}$ before specimen collection.

\section{DNA extraction}

DNA was extracted from the bacterial cells using GeneJET genomic DNA purification kit (Cat\#K0721, Thermo Fisher Scientific, USA) and following the manufacturer's protocol. Up to $2 \times 10^{9}$ bacterial cells were harvested in $1.5-\mathrm{ml}$ micro-centrifuge tubes by centrifugal for $10 \mathrm{~min}$ at $5000 \times$ $g$. Then, the resulting pellets were suspended in $180 \mu$ of digestion solution and $20 \mu$ of protein- ase $\mathrm{K}$ and incubated at $56^{\circ} \mathrm{C}$ in a thermo-mixer until complete lysis occurred ( $30 \mathrm{~min})$.

RNase A solution $(20 \mu \mathrm{l})$ was added and incubated for $10 \mathrm{~min}$ in order to obtain RNA-free samples. After $200 \mu \mathrm{l}$ of lysis solution and $400 \mu \mathrm{l}$ of ethanol (50\%) had been added and mixed thoroughly to the samples, the prepared lysate was transferred to the specified columns and centrifuged for $1 \mathrm{~min}$ at $6000 \times \mathrm{g}$. The DNA absorbed on the silica membrane was washed twice in $500 \mu l$ wash buffer I and II, respectively.

Then, the columns were centrifuged at full speed for $1 \mathrm{~min}$, in order to ensure elimination of all impurities. Finally, the columns were transferred to new $1.5-\mathrm{ml}$ collection tubes and $200 \mu$ l of elusion buffer was added; the tubes were incubated at room temperature for $2 \mathrm{~min}$ and then centrifuged at $8000 \times \mathrm{g}$ for $1 \mathrm{~min}$ to elute the DNA. The extracted DNA concentration and relating purity were assessed using NanoDrop ND-1000 (Nanodrop, USA).

\section{Real-time PCR}

The $M \beta$ L-encoding bla $a_{I M P}$ - and bla $a_{\mathrm{VIM}}$-type genes were detected via SYBR green multiplex real-time $P C R$ analysis. The following primers (Invitrogen, $C A$ ) were used for IMP: forward: 5'- GAATAG(A/G)(A/G) TGGCTTAA(C/T)TCTC-3'; reverse: 5' - CCAAAC(C/T) ACTA(G/C)GTTATC-3', for VIM: forward: 5'- GTTTGGTCGCA TATCGCAAC-3'; reverse: 5'-AATGCGCAGCACCAGGATAG-3', and for 16S rRNA as internal control: forward: 5'-AGAGTTTGATCCTGGCTCAG-3'; reverse: 5'-ACGGCTACCTTGTTACGACTT-3' at a final concentration $1.0 \mu \mathrm{M}, 0.1 \mu \mathrm{M}$, and $0.04 \mu \mathrm{M}$ for bla $a_{\mathrm{IMP}}$ bla $\mathrm{VII}_{\mathrm{V}}$, and 16S rRNA, respectively [17]. Amplification was performed in a $48-\mu l$ mixture containing three pairs of primers at their respective concentrations, $2 \mu \mathrm{l}$ of the template by using the DNA at concentration $100 \mathrm{pg} /$ reaction, $25 \mu \mathrm{l}$ of Platinum SYBR green qPCR SuperMix (Platinum Taq DNA polymerase, SYBR green I dye, Tris- $\mathrm{HCl}$, $\mathrm{KCl}, 6 \mathrm{mM} \mathrm{MgCl}, 400 \mu \mathrm{M}$ dGTP, $400 \mu \mathrm{M}$ dATP, $400 \mu \mathrm{M}$ dCTP, $800 \mu \mathrm{M}$ dUTP, uracil DNA glycosylase, and stabilisers- Cat. No. 11733-038, Invitrogen, CA).

Rox reference dye was included in each reaction to normalise the fluorescent reporter signal. The PCR was performed by StepOne ${ }^{T M}$ Real-Time PCR System manufactured by Biosystems, using the following conditions: initial denaturation at $94^{\circ} \mathrm{C}$ for $5 \mathrm{~min} ; 35$ cycles of $94^{\circ} \mathrm{C}$ for $20 \mathrm{~s}, 53^{\circ} \mathrm{C}$ for $45 \mathrm{~s}$, and $72^{\circ} \mathrm{C}$ for $30 \mathrm{~s}$. A melt curve step was prepared (from $68^{\circ} \mathrm{C}$ gradually increasing by $0.5^{\circ} \mathrm{C} / \mathrm{s}$ to $95^{\circ} \mathrm{C}$, with acquisition data every $1 \mathrm{~s}$ ).

Melt curves were then converted to melting peaks by plotting the negative derivative of fluorescence versus temperature $(-\mathrm{dF} 2 / \mathrm{dT}$ vs. T and $\mathrm{dF} 3 / \mathrm{dT}$ vs. T). Post-PCR agarose gel (1.5\%) containing $0.5 \mu \mathrm{g} / \mathrm{ml}$ ethidium bromide was performed; the predicted lengths of the amplicons were 188 , 
Table I. Geographic distribution of the patients studied according to the personal data of the cases $(n=65)[14]$

\begin{tabular}{|llc|}
\hline Variable & Results \\
\hline Gender & Male & $90(43.1 \%)$ \\
\cline { 2 - 3 } & Female & $120(56.9 \%)$ \\
\hline Age & & $42.9 \pm 18.1$ \\
\hline
\end{tabular}

382, and 1499 base pairs for bla $\mathrm{IMP}_{\mathrm{IM}}$ bla $a_{\mathrm{VIM}}$, and $16 \mathrm{~S}$ rRNA, respectively [17].

\section{Ethical considerations}

The study obtained approval from the Ethics Committee of the Faculty of Medicine, Suez Canal University (FOMSCU), Ismailia, Egypt.

\section{Statistical analysis}

Data was analysed by Texasoft WINKS, 4.651 software (Texasoft, Texas, USA). The numerical data were expressed as means and standard deviations. The qualitative data were expressed in frequencies and percentages. Student's $t$-test was applied in order to compare between two independent groups. Frequencies of categorical variables were compared using the $\chi^{2}$ test and Fishers' exact test when appropriate.

For quantitative data, the comparison between the three groups was performed by an analysis of variance (ANOVA) followed by post-hoc Newman-Keuls multiple comparison tests. A twotailed $p<0.05$ was considered significant.

\section{Results}

Geographic distribution of the patients studied according to the personal data of the cases presented in Table I.

Out of 65 Pseudomonas aeruginosa strains, the bla $a_{\mathrm{vIM}}$ gene was present in 4 females and 1 male, both with age $42.9 \pm 18$.1. Two cases were isolated from the Oncology Department, and one case each was from the Burn Unit, Surgery ward, and Intensive Care Unit. The most common specimen was pus and blood (Table II).

The $b a_{\mathrm{vIM}}$ gene is remarkably present among female patients (10.8\%) in the following departments: Intensive Care Unit, Oncology, Surgery, and Burn Unit at a percentage of 10, 9.5, 9, and 9, respectively. For the type of specimen, it is present at the highest level in blood specimens and was not present in urine.

The relationship between the bla ${ }_{\mathrm{vIm}}$ gene and the antibiotic sensitivity according to the disc diffusion method is presented in Table III. It is worth mentioning that this gene is present in different antibiotic groups such as ampicillin, piperacillin, ciprofloxacin, cefepime, and imipenem in the following percentages: 7.7, 8.2, 12.9, 12.2, and 16.0, respectively.

The bla $a_{\mathrm{vIM}}$ gene is expressed in four MDR strains by using MHT and EDTA-IMP DDST phenotypic confirmatory test (Table IV).

Table II. Association between demographic characteristics and blaVIM gene carriage among Pseudomonas aeruginosa isolates

\begin{tabular}{|c|c|c|c|c|c|c|}
\hline \multirow[t]{2}{*}{ Parameter } & \multirow[t]{2}{*}{$N$} & \multicolumn{4}{|c|}{$b l a_{\mathrm{vIM}}$ in study samples $(n=65)$} & \multirow[t]{2}{*}{$P$-value } \\
\hline & & Present & $\%$ & Absent & $\%$ & \\
\hline \multicolumn{6}{|l|}{ Gender: } & 0.380 \\
\hline Male & 28 & 1 & 3.6 & 27 & 96.4 & \\
\hline Female & 37 & 4 & 10.8 & 33 & 89.1 & \\
\hline \multicolumn{6}{|l|}{ Department: } & 0.941 \\
\hline Burn unit & 11 & 1 & 9 & 10 & 91 & \\
\hline Surgery & 11 & 1 & 9 & 10 & 91 & \\
\hline Oncology & 21 & 2 & 9.5 & 19 & 90.5 & \\
\hline Intensive care unit & 10 & 1 & 10 & 9 & 90 & \\
\hline Urology & 5 & 0 & 0 & 5 & 100 & \\
\hline $\begin{array}{l}\text { Neonatal intensive } \\
\text { care unit }\end{array}$ & 7 & 0 & 0 & 7 & 100 & \\
\hline \multicolumn{6}{|l|}{ Specimen: } & 0.771 \\
\hline Urine & 8 & 0 & 0 & 8 & 100 & \\
\hline Pus & 24 & 2 & 8.3 & 22 & 91.7 & \\
\hline Blood & 17 & 2 & 11.8 & 15 & 88.2 & \\
\hline Sputum & 16 & 1 & 6.3 & 15 & 93.7 & \\
\hline
\end{tabular}


Table III. Association between bla $a_{V I M}$ gene carriage and antibiotic sensitivity among Pseudomonas aeruginosa isolates

\begin{tabular}{|c|c|c|c|c|c|c|}
\hline \multirow[t]{2}{*}{ Variable } & \multirow[t]{2}{*}{$N$} & \multicolumn{4}{|c|}{ bla ${ }_{\mathrm{vIM}}$ in study samples $(n=65)$} & \multirow[t]{2}{*}{$P$-value } \\
\hline & & Present & $\%$ & Absent & $\%$ & \\
\hline Ampicillin: & & & & & & $<0.001^{*}$ \\
\hline Resistant & 65 & 5 & 7.7 & 60 & 92.3 & \\
\hline Piperacillin: & & & & & & 0.720 \\
\hline Resistant & 61 & 5 & 8.2 & 56 & 91.8 & \\
\hline Intermediate & 4 & 0 & 0 & 4 & 100 & \\
\hline Ciprofloxacin: & & & & & & 0.319 \\
\hline Sensitive & 32 & 1 & 3.1 & 31 & 96.9 & \\
\hline Resistant & 31 & 4 & 12.9 & 27 & 87.1 & \\
\hline Intermediate & 2 & 0 & 0 & 2 & 100 & \\
\hline Cefepime: & & & & & & 0.206 \\
\hline Sensitive & 20 & 0 & 0 & 20 & 100 & \\
\hline Resistant & 41 & 5 & 12.2 & 36 & 87.8 & \\
\hline Intermediate & 4 & 0 & 0 & 4 & 100 & \\
\hline Aztreonam: & & & & & & 0.684 \\
\hline Sensitive & 31 & 2 & 6.5 & 29 & 93.5 & \\
\hline Resistant & 28 & 2 & 7.1 & 26 & 92.9 & \\
\hline Intermediate & 6 & 1 & 16.7 & 5 & 83.3 & \\
\hline Gentamicin: & & & & & & 0.639 \\
\hline Sensitive & 45 & 3 & 6.7 & 42 & 93.3 & \\
\hline Resistant & 20 & 2 & 10 & 18 & 90 & \\
\hline Meropenem: & & & & & & 0.401 \\
\hline Sensitive & 41 & 2 & 4.9 & 39 & 95.1 & \\
\hline Resistant & 12 & 1 & 8.3 & 11 & 91.7 & \\
\hline Intermediate & 12 & 2 & 16.7 & 10 & 83.3 & \\
\hline Imipenem: & & & & & & 0.129 \\
\hline Sensitive & 29 & 1 & 3.4 & 28 & 96.6 & \\
\hline Resistant & 25 & 4 & 16.0 & 21 & 84.0 & \\
\hline Intermediate & 11 & 0 & 0 & 11 & 100 & \\
\hline
\end{tabular}

For the bla $a_{\text {mp }}$ gene, it was not expressed in any strain in any of the 65 samples.

\section{Discussion}

Drug-resistant Pseudomonas aeruginosa is considered a major problem, and several antibiotics such as $\beta$-lactamases, quinolones, and aminoglycosides are used to solve this problem [18]. The antibiotic resistance pattern fluctuates, especially in the case of imipenem [19]. Carbapenems are often used to treat MDR Pseudomonas aeruginosa [20]. The production of M $\beta$ Ls enzymes (IMP and VIM) is considered to be the cause of antibiotic resistance to imipenem $[21,22]$.
Literature reports that there are several phenotypic methods used to detect $M \beta L s$, but their role is limited because not all $M \beta$ Ls carry the same enzyme [23, 24].

The $M \beta L$ s producing Pseudomonas aeruginosa in Egypt vary according to the infection control policies and procedures applied in hospitals. The sample size of the population studied in one study [25] was estimated at $82 \%$, while in another it was very low, reaching just $32.3 \%$ [26].

In the present study, bla $a_{V I M}$ is the gene detected in all isolates. This copes with several studies recognising that this is dominant worldwide and associated with hospital-acquired outbreaks [27, 
Table IV. Association between bla $_{V I M}$ gene carriage and the phenotypic confirmatory methods

\begin{tabular}{|c|c|c|c|c|c|c|}
\hline \multirow[t]{2}{*}{ Parameter } & \multirow[t]{2}{*}{$N$} & \multicolumn{4}{|c|}{$b l a_{\mathrm{VIM}}$ in study samples $(n=65)$} & \multirow[t]{2}{*}{$P$-value } \\
\hline & & Present & $\%$ & Absent & $\%$ & \\
\hline \multicolumn{6}{|l|}{ Multi-drug resistance: } & 0.174 \\
\hline Present & 33 & 4 & 12.1 & 29 & 87.9 & \\
\hline Absent & 32 & 1 & 3.1 & 31 & 96.9 & \\
\hline \multicolumn{6}{|l|}{ MHT: } & 0.222 \\
\hline Total isolated $P$. aeruginosa & 35 & 4 & 11.4 & 31 & 88.6 & \\
\hline MDR strains & 20 & 1 & 3.3 & 29 & 96.7 & \\
\hline \multicolumn{6}{|l|}{ DDST: } & 0.013 \\
\hline Present & 20 & 4 & 20.0 & 16 & 80.0 & \\
\hline Absent & 45 & 1 & 2.2 & 44 & 97.8 & \\
\hline
\end{tabular}

28]. M $\beta$ Ls producing isolates is a nationwide concern in Egypt, and many efforts are being made to confront it in order to decrease morbidity and mortality.

The bla $a_{I M P}$ gene was not expressed in any strain among the population studied. This is in agreement with the study by Shahcheraghi et al. conducted in Imam Khomeini Hospital in Tehran on 243 Pseudomonas. aeruginosa strains because the study did not observe the $b_{1 a_{I M P}}$ gene among the isolates [29].

Fazeli et al. conducted their study of Pseudomonas aeruginosa $M \beta L S$ (sensitive to both imipenem and meropenem) by sing PCR technique. However, no bla ${ }_{I M P}$ gene was expressed among all the samples [30].

The study results were limited to a sample of 65 isolates. The reason behind this was due to insufficient financial support and the short duration of the study period. However, we anticipate the expansion of the work on a large sample size over a longer period.

In conclusion, the problem of $M \beta L$ s and carbapenem resistance requires ongoing surveillance, strong preventive measures, and implementation of infection-control policies and procedures. Also, routine diagnostic laboratory methods should be performed as well as synthesis of antimicrobial products, and new effective mechanisms should be introduced.

\section{Acknowledgments}

The authors would like to thank the Oncology Diagnostic Unit, Suez Canal university, Ismailia, Egypt for providing the facilities in order to pursue work for this research.

\section{Conflict of interest}

The authors declare no conflict of interest

\section{References}

1. Lucia A, de Freitas P, Barth AL. Antibiotic resistance and molecular typing of Pseudomonas aeruginosa: focus on imipenem. Brazil J Infect Dis 2002; 6: 1-7.

2. Cabot G, Ocampo-Sosa AA, Dominguez MA, et al. Spanish Network for Research in Infectious Diseases (REIPI): genetic markers of widespread extensively drug-resistant Pseudomonas aeruginosa high-risk clones. Antimicrob Agents Chemother 2012; 56: 6349-57.

3. Poole K. Pseudomonas aeruginosa: resistance to the max. Front Microbiol 2011; 2: 65.

4. Lee JY, Ko KS. OprD mutations and inactivation, expression of efflux pumps and AmpC, and metallobeta-lactamases in carbapenem-resistant Pseudomonas aeruginosa isolates from South Korea. Int J Antimicrob Agents 2012; 40: 168-72.

5. Wang J, Zhou JY, Qu TT, et al. Molecular epidemiology and mechanisms of carbapenem resistance in Pseudomonas aeruginosa isolates from Chinese hospitals. Int J Antimicrob Agents 2010; 35: 486-91.

6. Lister PD, Wolter DJ, Hanson ND. Antibacterial-resistant Pseudomonas aeruginosa: clinical impact and complex regulation of chromosomally encoded resistance mechanisms. Clin Microbiol Rev 2009; 22: 582-610.

7. Garau G, GarcSez I, Bebrone C, et al. Update of the standard numbering scheme for class B-lactamases. Antimicrob Agents Chemother 2004; 48: 2347-9.

8. Golshani B, Lamotte-Brasseur J, Rossolini GM, et al. Standard numbering schemefor class (B)-lactamases. Antimicrob Agents Chemother 2005; 45: 660-3.

9. Zhou F, Ji B, Zhang $\mathrm{H}$, et al. Synergistic effect of thymol and carvacrol combined with chelators and organic acids against Salmonella typhimurium. J Food Prot 2007; 70: 1704-9.

10. Libisch B, Balogh B, Fuzi M. Identification of two multidrug-resistant Pseudomonas aeruginosa clonal lineages 
with a countrywide distribution in Hungary. Curr Microbiol 2009; 58: 111-6.

11. Fiett J, Baraniak A, Mrowka A, et al. Molecular epidemiology of acquired-metallo-beta-lactamase-producing bacteria in Poland. Antimicrob Agents Chemother 2006; 50: 880-6.

12. Kouda S, Ohara M, Onodera M, et al. Increased prevalence and clonal dissemination of multidrug-resistant Pseudomonas aeruginosa with the blalMP-1 gene cassette in Hiroshima. J Antimicrob Chemother 2009; 64: 46-51.

13. Upadhyay S, Sen MR, Bhattacharjee A. Presence of different beta-lactamase classes among clinical isolates of Pseudomonas aeruginosa expressing AmpC beta-lactamase enzyme. J Infect Dev Ctries 2010; 4: 239-42.

14. El-Maraghy NN, El-Hadidi GS, Mansour MK, El-Saeiyed MM. Detection of metallo-beta-lactamase enzyme among isolated Pseudomonas aeruginosa from nosocomial infected patients at Suez Canal University Hospital. Int J Curr Microbiol App Sci 2015; 4: 191-202.

15. Lee $\mathrm{K}$, Lee WG, Uh $\mathrm{Y}$, et al. Nationwide surveillance of antimicrobial resistance Group. VIM- and IMP-type metallo-lactamase-producing Pseudomonas spp. and Acinetobacter spp. in Korean hospitals. Emerg Infect Dis 2003; 9: 868-71.

16. Yang Y, Livermore DM. Biochemical characterization of a beta-lactamase that hydrolyzes penems and carbapenems from two Serratia marcescens isolates. Antimicrob. Agents Chemother 1990; 34: 755-75.

17. Mendes RE, Kiyota KA, Monteiro J, et al. Rapid detection and identification of metallo-beta-lactamase-encoding genes by multiplex real-time PCR essay and melt curve analysis. J Clin Microbiol 2007; 45: 544-7.

18. Song JH, Chung DR. Respiratory infections due to drug-resistant bacteria. Infect Dis Clin North Am 2010; 24 : 639-53.

19. Patzer JA, Dzierzanowska D. Increase of imipenem resistance among Pseudomonas aeruginosa isolates from a Polish paediatric hospital (1993-2002). Int J Antimicrob Agents 2007; 29: 153-8.

20. Sunagawa M, Kanazawa K, Nouda H. Antipseudomonal activity of carbapenem antibiotics. Jpn J Antibiot 2000; 53: 479-511.

21. Senda K, Arakawa Y, Ichiyama S, et al. PCR detection of metallo-beta-lactamase gene (blalMP) in gram-negative rods resistant to broad-spectrum beta-lactams. J Clin Microbiol 1996; 34: 2909-13.

22. Niitsuma K, Saitoh M, Kojimabara M, et al. Antimicrobial susceptibility of Pseudomonas aeruginosa isolated in Fukushima Prefecture. Jpn J Antibiot 2001; 54: 79-87.

23. Arakawa Y, Shibata N, Shibayama K, et al. Convenient test for screening metallo-beta-lactamase-producing Gram-negative bacteria by using thiol compounds. J Clin Microbiol 2000; 38: 40-3.

24. Toleman MA, Rolston K, Jones RN, Walsh TR. blaVIM-7, an evolutionarily distinct metallo-beta-lactamase gene in a Pseudomonas aeruginosa isolate from the United States. Antimicrob Agents Chemother 2004; 48: 329-332.

25. Diab M, Fam N, El-Said M, El-Dabaa E, El-Defrawy I, Saber M. Occurrence of VIM-2 Metallo-beta- lactamases in imipenem resistant and susceptible Pseudomonas aeruginosa clinical isolates from Egypt. Afr J Microbiol Res 2013; 7: 4465-72.

26. Mansour SA, Eldaly O, Fatani AJ, Mohamed ML, Ibrahim EM. Epidemiological characterization of P. aeruginosa isolates of intensive care units in Egypt and Saudi Arabia. East Mediterr Health J 2013; 19: 71-80.
27. Walsh TR, Li H, Toleman MA, Bennett PM, Jones RN. Complete sequence of $p$ 07-406, a 24,179-base-pair plasmid harboring the blaVIM-7 metallo-beta-lactamase gene in a Pseudomonas aeruginosa isolate from the United States. Antimicrob Agents Chemother 2008; 52: 3099-105.

28. Elias J, Schoen C, Heinze G, et al. Nosocomial outbreak of VIM-2 metallo-beta-lactamase-producing Pseudomonas aeruginosa associated with retrograde urography. Clin Microbiol Infect 2010; 16: 1494-500.

29. Salami H, Owlia P, Yakhchali B, Rastegarlari A. Drug susceptibility and molecular epidemiology of Pseudomonas aeruginosa isolated in a burn unit. J Infect Dis 2009; 5: 308-13.

30. Fazeli H, Sadighian H, Nasr Esfahani B, Pourmand MR. Idenfication of class-1 integron and various beta-lactamase classes among clinical isolates of Pseudomonas aeruginosa at Children's Medical Center Hospital. J Med Bacteriol 2012; 1: 25-36. 